\title{
EL TEATRO Y LAS IDEAS
}

\section{Julio Godoy Rojas}

Una es la forma teatral - estructura cambiante en la que se moldea el discurso dramático - y otra, la esencia teatral - exteriorización del instinto de transfiguración que alienta al ser. Uno es el espectáculo escénico - síntesis de arte interpretativo, de creación escenográfica y de acción mímica - y otra la literatura teatral - expresión dialéctica a través de la cual se manifiesta la imaginación creadora del autor. Es decir, cuatro aspectos, cuatro circunstancias distintas pero un solo objetivo: creación de la magia teatral, la que a través de lo visual y auditivo envolverá al espectador y tratará

de apresarlo, aunque sea por un instante, en un mundo distinto del que habitualmente lo oprime.

Pero esas cuatro circunstancias que, unidas, brindan lo mágico del teatro de la realización escénica, ¿alcanzan validez separadamente?

Es cierto que el espectáculo y la forma teatral existen sin la literatura dramática - la danza y el mimo -, como así también esta última sin aquellas. La obra es un fin en sí misma. No necesita de la representación para tener vigencia. Para comprender a Shakespeare o Racine, a Ibsen o Sarte, a Beckett o Brecht no necesitamos ver sus obras a través del espectáculo escénico. Nos basta penetrar en ellas a través de la lectura, dado que la esencia está en el pensamiento del autor y es el lector quien integrará la síntesis de la representación a través de la imaginación.

Los críticos señalan que el texto dramático se escribe para ser representado. Es lógico que así sea; pero es evidente también que su vigencia no depende sólo de la representación sino de su propia creación y de los valores intrínsecos que la hacen perdurar. Existe, por lo tanto, una literatura dramática que, representada o no, tiene validez como expresión creadora del pensamiento. $\mathrm{Y}$ es precisamente esa literatura la que trasciende y perdura independientemente de la representación.

Esta substancia literaria es la que a lo largo de la historia constituye el contenido fundamental del teatro. Pero, siendo el teatro un juego en el que el hombre busca satisfacer su apetencia lúdica, es natural que la imaginación participe en forma preponderante. El vuelo imaginativo del autor dará así oportunidad a que el lector o el espectador viva a través de los distintos personajes las distintas circunstancias que, de otra manera - en la vida real, cotidiana no podrá hacerlo. Es decir, encontrará una posibilidad de ser que concretizará su deseo - casi siempre inconsciente - de ser distinto, de querer vivir una vida que no le es dada en su cotidianeidad. 
Si el teatro se transforma de esta manera en motor de ese sentimiento de libertad que es innato en el hombre, es indudable que tal manifestación del quehacer intelectual se manifieste propicia a exceder la realidad, tratando de descubrir aspectos nuevos, desconocidos.

El artista y el escritor buscan permanentemente la verdad; pero ésta no es para ellos la preestablecida por conceptos tradicionales, estáticos. Lo cotidiano no deja por ello de estar reflejado en sus obras; sólo que no aparecerá representado con un sentido auténtico, verídico.

Cuando Ionesco señala que una cosa dicha ya está muerta, que la realidad está más allá, no quiere significar que lo realizado debe desecharse por caduco, sino que frente al constante dinamismo de la vida, el arte y la literatura deben estar permanentemente alerta. El hombre de pensamiento mira siempre hacia delante, siendo esta su más grande virtud. Pero ese mirar en el tiempo y en el espacio, esa ansia de futuro, tampoco debe servir como coraza para aislarse del presente.

El libre albedrío es fuente creadora, pero el arte y la literatura tienen también una función social que cumplir, si bien es cierto que esta no puede ni debe regir la concepción de la obra.

El pintor contemporáneo considera, como Merleau-Ponty, que el sentido de la cosa habita en ella y otorga al objeto una vivencia que va más allá de la simple forma. De la misma manera, el dramaturgo actual trata de tomar la verdad, el sentido de la vida, la trascendencia ontológica de cada acto del hombre, y descompone lo aparentemente real otorgando validez propia a cada elemento de esa realidad. Mediante este proceso de abstracción pretende ir en busca de la verdad. Y esto supone de por sí cumplimentar una función de proyección social, ya que con tal búsqueda se propone crear una conciencia individual que capacite al hombre para la comprensión de los problemas que se relacionan con su existir: tanto como ser-en-sí, que como ser-en-el-mundo.

Vivimos en un mundo globalizado, un mundo en el que el adelanto de la técnica ha trastocado todo: la vida material tanto como la vida espiritual. El mismo comportamiento ético del hombre ha sufrido una indudable conmoción, hasta tal punto de que lo moral pareciera tener validez sólo cuando no es traba para la consecución de un logro utilitario. El confort proporcionado por esa técnica, por otra parte, ha llevado al hombre a un incontrolable deseo de querer gozar de todo el bienestar material posible, desechando para ello principios que parecían inconmovibles. Se ha perdido, asimismo, en gran parte, el sentido de la responsabilidad, dándose la paradoja de que mientras tratarnos ansiosamente de elevarnos hacia el espacio en busca de otros mundos, no sabemos mantenernos en la tierra con la dignidad que nos debiera otorgar nuestra calidad de ser pensante.

Frente a tal panorama, ¿qué puede hacer el artista y el literato? ¿Quedar como simple espectador de un mundo enrevesado o tomar posición beligerante? Creemos que esto último, pero siempre que ello no importe atribuirse funciones que corresponden al político, al economista o al hombre de ciencia. 
El poeta, el artista y el escritor trabajan con elementos de indole especial, como que buscan repercutir en lo más intimo del ser. Son materiales subjetivos cuyo acento sólo encontrará eco en los sentimientos más puros del hombre y que deberán obrar, no por coacción, sino por convencimiento.

El hombre debe necesariamente ubicarse en el tiempo. Para ello es preciso comprender todo el proceso que se desenvuelve a su alrededor. Aferrarse al pasado por un mero sentimiento tradicional o mantenerse a la defensiva en el presente por simple conformismo, es una falsa posición que invariablemente lo llevará a un desconocimiento parcial o total de la realidad. El prejuicio lo incapacitará entonces para comprender cualquier intento de reforma o innovación. $\mathrm{Y}$ como las creaciones del arte y de las letras son por lo general potencialmente revolucionarias, puesto que aspiran a concretar principios que deparen a la sociedad otros horizontes más halagüeños, se da la situación del distanciamiento espiritual del escritor y artista con la masa, hecho que alcanza mayor intensidad en momentos en que, como en los últimos treinta años, la inquietud renovadora de aquellos está insuflada de una vital búsqueda de nuevos valores estéticos y humanos.

El acercamiento, sin embargo, no podrá producirse sino por el camino de la cultura. No es el arte el que debe resignar a su jerarquía de valores y a su posición de vanguardia espiritual para halagar al pueblo, sino éste quien debe tratar de elevarse hacia el arte. El teatro, escrito para lograr la fácil aceptación de la masa, lo fue a veces a costa de su calidad estética y de la autenticidad de su mensaje. Por otra parte, es necesario, por una razón de educación, que el escritor contemporáneo trabaje para sus contemporáneos, pero haciendo lo que ellos necesiten y no lo que alaben.

Alguien señaló, alguna vez, que pensar en saborear; muy buena definición dado que saborear supone la desintegración de los elementos constitutivos para poder alcanzar lo máximo de lo que se gusta. Saborear la vida, a través del pensamiento, lleva implícito entonces un proceso de abstracción que es precisamente lo que realiza el autor teatral contemporáneo - y en forma expresa en el llamado antiteatro - para quien el problema - tal como lo señala Ionesco - es simplemente descubrir verdades y decirlas. Claro que estas verdades no serán las que están al alcance de la masa indiferente, sino aquellas que el escritor hallará "saboreando" los sucesos que transcurren a su alrededor o que él, personalmente, los vive.

Un teatro que va en busca de un propósito que no es el inmediato de la simple distracción o de la propaganda dogmática, es un teatro que necesariamente requiere una especial comprensión. Pero, como él es la expresión intelectual de una época - y ésta a su vez consecuencia de variadas circunstancias políticas, sociales, económicas y científicas -, la comprensión debe llegar fortuitamente a través de una compenetración del hombre con el momento histórico, de modo que la percepción del contenido de su obra - no de su tema, su argumento -, alcance la repercusión necesaria en su espíritu como para conmoverlo e incitarlo a pensar por sí mismo.

La misión del escritor es social, pero no política. Su obra está destinada a lograr una preocupación que, trascendiendo de la anécdota, deje en el espectador o lector un sedimento 
capaz de mantener latente la siempre encendida fe en la superación constante de la humanidad por el camino, poco transitado hasta ahora, de la libertad y la justicia. Su compromiso no puede ser otro, por consiguiente, que con el hombre mismo.

Creemos que los que creen que las poesías no deben contener ninguna idea, se engañan; al contrario, ellas tienen que contenerla, pues la idea es la intención fundamental del poeta, el sentido básico de su obra.

El teatro actual de vanguardia es precisamente un teatro de ideas, pero no de tesis, que es otra cosa muy diferente. Quien pretende que el teatro sirva en un determinado momento a un fin determinado, no busca ya la concreción de una dramática de ideas, dinámica en su busca de verdades, sino una fría exposición de motivos que, lejos de inquietar a la masa, la paralice en su emoción con el martillazo de una verdad impuesta. Tal teatro podrá conmover a quienes está dirigido, pero carecerá de la fuerza indispensable para trascender temporalmente y ser expresión del espíritu creador de la época, libremente manifestado.

Tomemos como ejemplo Esperando a Godot, de Samuel Beckett, obra estrenada en 1953 y que ha merecido desde entonces innumerables comentarios críticos.

A través de un diálogo vivaz, a veces incoherente, siempre agudo, fluctúa la ida no materializada en ningún argumento, sino en esa angustiosa espera de Estragón y Vladimiro, actitud que concreta la esperanza del hombre y su incapacidad para quebrar la inmovilidad y realizar su ansiada libertad.

El pensamiento del autor da substancia a la obra, pero sólo a través de la actitud de sus personajes: espera y ausencia; querer y no poder; angustia de una soledad existencial y absurdo de un mundo que al fin no nos pertenece. ¿Para qué más? ¿Para qué el argumento, la acción, la tesis, cuando con el solo vibrar de una idea se logra crear una obra esencialmente teatral y de profunda proyección humana?

Lo superfluo no interesa a Beckett, como tampoco a la mayoría de los que consideran a la obra teatral como genuino producto de una límpida y auténtica exigencia del espíritu.

Un teatro así, que se nutre de la más rica imaginación, que surge de la más pura intuición del autor, pero en el cual está presente el hombre con todas sus vivencias, creemos que es un teatro que no necesita de los elementos exteriores de la realidad cotidiana para consubstanciarse con el pueblo y cumplir con su función social. 